\title{
Suppression of inflammatory mediators by aqueous leaf extract of Crotalaria verrucosa: in vivo and in vitro analysis
}

\author{
Mohammad Mustakim Billah" ${ }^{1 *}$, Abir Huzaifa ${ }^{2}$, M. Abdul Kader Khan ${ }^{3}$, Nusrat Jahan Vabna ${ }^{4}$, \\ Kashfia Nawrin', M. Abu Rayhan ${ }^{5}$
}

\author{
${ }^{1}$ Department of Pharmacology, Institute for Pharmaceutical Skill Development and Research, Dhaka, Bangladesh \\ ${ }^{2}$ Department of Pharmacy, East West University, Dhaka, Bangladesh \\ ${ }^{3}$ Department of Pharmacy, University of Rajshahi, Rajshahi, Bangladesh \\ ${ }^{4}$ Department of Pharmacy, University of Asia Pacific, Dhaka, Bangladesh \\ ${ }^{5}$ National Cancer Center-Graduate School of Cancer Science and Policy, Goyang-si Gyeonggi, South Korea
}

Received: 19 September 2020

Accepted: 28 October 2020

\section{*Correspondence:}

Mohammad Mustakim Billah,

Email: mustakimbillah@hotmail.com

Copyright: ( $)$ the author(s), publisher and licensee Medip Academy. This is an open-access article distributed under the terms of the Creative Commons Attribution Non-Commercial License, which permits unrestricted non-commercial use, distribution, and reproduction in any medium, provided the original work is properly cited.

\begin{abstract}
Background: Crotalaria verrucosa is a traditional plant frequently prescribed by the tribes for its medicinal value against inflammation. The present study was designed to investigate the scientific basis for medicinal value in inflammation by in vivo and in vitro analysis.

Methods: Anti-inflammatory activity of the plant's leaf was evaluated by two in vivo methods - carrageenan induced rat paw edema and xylene induced mice ear edema. Moreover, in vitro analysis was performed through heat induced hemolysis and heat induced protein denaturation methods.

Results: The inflammation produced by carrageenan and xylene were effectively suppressed by the aqueous leaf extract of C. verrucosa (CVAQ) at $600 \mathrm{mg} / \mathrm{kg}$ body weight which was comparable to the standards. In heat induced hemolysis test the extract was able to inhibit the lysis up to $70 \%$ at $500 \mu \mathrm{g} / \mathrm{ml}$ whereas in heat induced protein denaturation test it reduces the percentage till $69 \%$ at the same concentration.

Conclusions: The findings suggested that CVAQ possess moderate to high anti-inflammatory activity when applied in low to high concentrated doses. However, the study can only conclude from this basic evaluation that the extract needs to be further investigated for identifying the potential compound which contributed to such medicinal value of the plant.
\end{abstract}

Keywords: Anti-inflammatory activity, Crotalaria verrucosa, Paw edema, Ear edema, Protein denaturation, Haemolysis

\section{INTRODUCTION}

The use of medicinal plants in the treatment of diseases is common from the ancient time till date. According to World health organization $80 \%$ of the populations in developing countries rely on the traditional medicines for their primary treatments. ${ }^{1}$ The discovery of many essential phytocompounds and their traditional use together found to attract the bio-model researchers and triggered for pharmacological investigations. As part of this, thousands of medicinal plants being traditionally used in Bangladesh are under investigation for their scientific basis of efficacy. The principle objective of these studies is to find responsible compounds or fractions to suggest the best preparation of traditional medicine, to get the optimum effect as well as to take approach to extract or synthesize such compound for 
allopathic preparation through research and development. $^{2}$

Crotalaria verrucosa, commonly known as blue rattlesnake, is a member of Leguminosae (family: Fabaceae). ${ }^{3}$ So far it has been reported as the only perennial shrub solely possessing medicinal value among Crotalaria species. They are found in unploughed land of Chittagong, Rajshahi, Mymensingh, Khulna, Sylhet districts of Bangladesh. ${ }^{4}$ The plant is a branched herbaceous shrub, grows up to $80-100 \mathrm{~cm}$ high which rises to triangular branches with $5-15 \mathrm{~cm}$ ovate deltoid leaves. Its leaf extract which contains tropane alkaloids, is considered efficacious in decreasing salivation and also used in impetigo and scabies. ${ }^{5}$ It also contains crotaverine, anacrotine and O12-acetyl-crotaverine. Researchers have found its effectiveness in dyspepsia, cough, biliousness, cardiac abnormalities and other oral disease. Tribal people use it as traditional medicine in skin allergies in different countries. ${ }^{4}$ Moreover, its hepatoprotective, antifertility activity and efficacy against estrogenic implantation has also been reported. ${ }^{6}$ The present study was designed to investigate its antiinflammatory response with aqueous leaf extract by established methods. Such investigation has not been reported in any literature.

\section{METHODS}

\section{Collection of plant leaf}

The leaves of Crotalaria verrucosa were collected from the hilly areas of Mymensingh district of Bangladesh on April when the leaves were in abundance. A sample specimen was sent to Bangladesh National Herbarium (BNH), Mirpur, Dhaka and authenticated with Accession number: DACB 42010.

\section{Preparation of extract}

Leaves were thoroughly washed after collection and dried under ceiling fan. The dried leaves were then grinded into powder (approx. $500 \mathrm{gm}$ ) by a grinding machine and soaked in water (2L) for 3 days with rigorous shaking. The mixture was filtrated with filter paper and the filtrate was inspissated using a rotary evaporator to obtain the viscous aqueous extract (approx. $5 \mathrm{gm}$ ) of Aqueous extract of $C$. verrucosa (CVAQ). Obtained extract was finally stored in air tight container till its use.

\section{Drugs and chemicals}

Prednisolone, indomethacin, xylene, carrageenan, acetyl salicylic acid used in experiments were collected from Merk, Germany.

\section{Acute toxicity study}

Separate acute toxicity tests were performed for Wister rat and Swiss Albino mice. Five groups $(n=5)$ of each type of animal were given high dose of the plant extract $(500 \mathrm{mg} / \mathrm{kg}, 1000 \mathrm{mg} / \mathrm{kg}, 1500 \mathrm{mg} / \mathrm{kg}$ and $2000 \mathrm{mg} / \mathrm{kg}$ ) and compared with a control (water) group. Animals were observed for next 72 hours for mortality, disorders and abnormal behavior.

\section{In vivo anti-inflammatory tests}

\section{Approval of institutional ethical committee}

The standard guideline for treating and handling animals adopted by Institutional ethical committee (Ref. no. IPSDRLAB/AHCP/01/18) was pursued for in vivo tests.

\section{Xylene induced ear edema}

The experiment xylene induced ear edema was undertaken as described by Tang et.al with slight modification. ${ }^{7}$ Swiss albino mice, weighing 22-28 gm of both sexes were taken. They were divided into six groups $(\mathrm{N}=5)$; control (water), test drugs (CVAQ $200 \mathrm{mg} / \mathrm{kg}$, CVAQ $400 \mathrm{mg} / \mathrm{kg}$, CVAQ $600 \mathrm{mg} / \mathrm{kg}$ body weight) and standards (indomethacin $10 \mathrm{mg} / \mathrm{kg}$ and prednisolone 5 $\mathrm{mg} / \mathrm{kg}$ body weight) were administered orally to the animals prior the bilateral application of xylene (inflammatory substance) to the right ear of each mouse. After 15 minutes, animals were sacrificed by dislocating their spinal cord from the neck and both ears were removed from test, standard and control animal. A $0.3 \mathrm{~cm}$ diameter circular area was cut from each ear of the animal. The weights of control (left) and inflamed ear (right) were taken and difference was calculated.

\section{Carrageenan induced rat paw edema}

The method was performed as described by Winter et. al with slight modifications. ${ }^{8,9}$ Both male and female Wister rat weighing 130-150 mg were taken and grouped as the experiment above ( $\mathrm{N}=5)$. Test drug (CVAQ $200 \mathrm{mg} / \mathrm{kg}$, CVAQ $400 \mathrm{mg} / \mathrm{kg}$, CVAQ $600 \mathrm{mg} / \mathrm{kg}$ body weight) and standard drugs (Indomethacin $10 \mathrm{mg} / \mathrm{kg}$ and prednisolone $5 \mathrm{mg} / \mathrm{kg}$ body weight) were administered orally to the animals 1 hour prior to injection of carrageenan (inflammation inducer) to the right paw while its left paw was left untreated to serve as its own control. Paw thickness was measured by vernier calipers measurement scale before the carrageenan injection as a base value. Thickness of the paw were again measured after treatment in intervals $(1,2,3,4$ and 24 hours after injection).

\section{In vitro anti-inflammatory tests}

\section{Heat induced hemolysis}

Fresh whole blood was collected from a healthy volunteer and washed it with $0.9 \%$ normal saline. It was then centrifuged at $3000 \mathrm{rpm}$ for 10 minutes. A $10 \% \mathrm{v} / \mathrm{v}$ HRBC suspension was obtained using isotonic phosphate buffer $(154 \mathrm{mM} \mathrm{NaCl}$ in $10 \mathrm{mM}$ sodium phosphate buffer 
at $\mathrm{pH} 7.4) .1 \mathrm{ml}$ phosphate buffer [pH 7.4, 0.15 M], $2 \mathrm{ml}$ hyposaline [0.36\%], $0.4 \mathrm{ml} \mathrm{HRBC}$ suspension with 0.6 $\mathrm{ml}$ of aqueous extracts of different concentrations (100, $200,300,400,500 \mu \mathrm{g} / \mathrm{ml}$ ) or same concentrations of acetyl salicylic acid for a standard or distilled water for control constituted the final reaction mixture $(4 \mathrm{ml})$. The mixture was then incubated for 30 minutes at $37^{\circ} \mathrm{C}$. After incubation the mixture was centrifuged at $3000 \mathrm{rpm}$ for 20 minutes. The supernatant was separated and its absorbance was taken at $560 \mathrm{~nm}$ using UV spectrophotometer. ${ }^{10}$

\section{Heat induced protein denaturation}

The method used for extraction of egg albumin was described by S.J. Carter. ${ }^{11}$ A reaction mixture was prepared for the investigation of the inhibition capacity of albumin denaturation. The mixture contained $0.2 \mathrm{ml}$ of egg albumin, $32.8 \mathrm{ml}$ of phosphate buffer saline ( $\mathrm{pH} 6.4)$ and $2 \mathrm{ml}$ of CVAQ extract at various concentration (100, 200, 300, 400, $500 \mu \mathrm{g} / \mathrm{ml})$. Aspirin at the same doses and distilled water served as the standard and control respectively. The mixture was filled in tubes to incubate at $37^{\circ} \mathrm{C}$ for 10 minutes. After incubation the mixture containing tubes were heated at $70^{\circ} \mathrm{C}$ for 5 minutes. The mixture was then left to be cooled. The UV spectrophotometer was used to measure its absorbance at $660 \mathrm{~nm}$.

\section{Statistical analysis}

Data obtained were analyzed via statistical analysis of variance (ANOVA) method using SPSS 24 for Windows and assessed for the significance of the result at $95 \%$, $99 \%$ and $99.99 \%$ confidence level and denoted respectively as $\mathrm{p}$ values $<0.05,0.01$ and 0.001 . All results were compared with the negative control.

\section{RESULTS}

\section{Acute toxicity study}

The acute toxicity study resulted with no morbidity or abnormal condition for the treated groups of animals. The study suggested a safe dose line for further experiments.

\section{In vivo anti-inflammatory tests}

\section{Xylene induced ear edema}

Xylene increased the edema by producing inflammation in control group. In response to the treatment, prednisolone and indomethacin decreased the inflammation which increased their percentage of inhibition as $78 \%$ and $56 \%$ respectively. The aqueous extract at $600 \mathrm{mg} / \mathrm{kg}$ body weight was able to exhibit maximum potential to suppress $(54 \%)$ edematous condition which was comparable to indomethacin at 10 $\mathrm{mg} / \mathrm{kg}$ body weight. However, CVAQ at 200 and 400 $\mathrm{mg} / \mathrm{kg}$ doses could not produce significant activity.

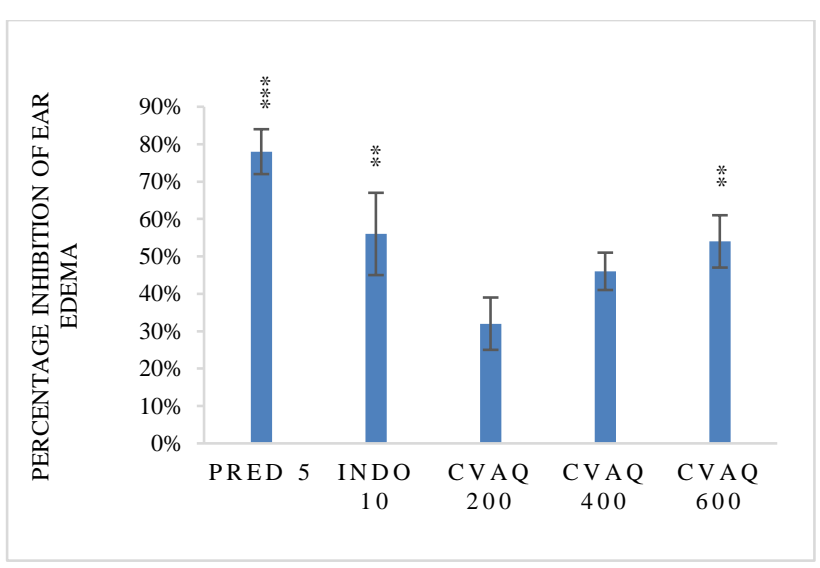

Figure 1: Percentage inhibition of ear edema in xylene induced ear edema test.

Figure represented the percentage inhibition of ear edema induced by xylene in respective groups of Swiss Albino mice. CVAQ = Aqueous extract of C. verrucosa, $\mathrm{PRED} 5=$ Prednisolone $5 \mathrm{mg} / \mathrm{kg}$ body weight, INDO $10=$ Indomethacin $10 \mathrm{mg} / \mathrm{kg}$ body weight. Data represented as mean+SEM and analyzed by one-way ANOVA followed by Dunnett $t$ test where $* *$, *** denoted $\mathrm{p}<0.01$ and $\mathrm{p}<0.001$ respectively and as statistically significant. All groups $(n=6)$ were compared to control.

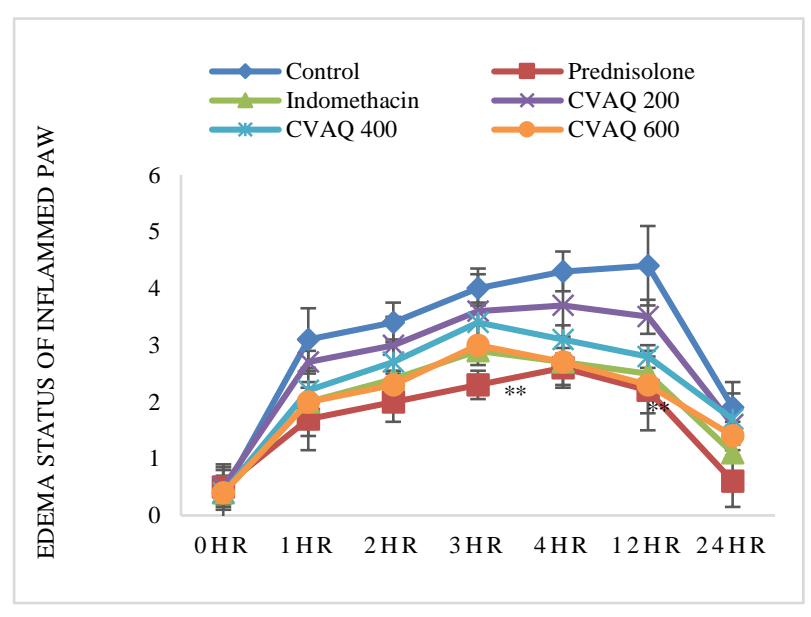

Figure 2: Edema status of inflamed paw in carrageenan induced paw edema test.

Figure represented the thickness of paw measured in $\mathrm{cm}$ inflamed by carrageenan in respective groups of Wister Rat. $\mathrm{CVAQ}=$ Aqueous extract of $C$. verrucosa . Data represented as mean+SEM and analyzed by one-way ANOVA followed by Dunnett $\mathrm{t}$ test where $* *$ denoted $\mathrm{p}<0.01$ as statistically significant. All groups $(n=6)$ were compared to control.

Carrageenan showed inflammatory response form the first hour of the treatment and increased the edematous condition gradually in next hours. Prednisolone was found to be highly effective in reducing the edema in all intervals compared to control whereas indomethacin mimicked prednisolone closely in suppressing the inflammation (Figure 2). Like xylene test, CVAQ 600 showed to be effective as indomethacin from 0-12 hrs, though in low dose exhibited with mild response. 


\section{In vitro anti-inflammatory tests}

\section{Heat induced hemolysis}

A standard curve was drawn with the applied concentration of acetyl salicylic acid to compare with that of the aqueous extract (Figure 3). The curves showed gradual increase in percentage of inhibition with increased concentration. The concentration $500 \mu \mathrm{g} / \mathrm{ml}$ was found to be most effective to inhibit hemolysis for both ASA (82\%) and CVAQ (70\%).

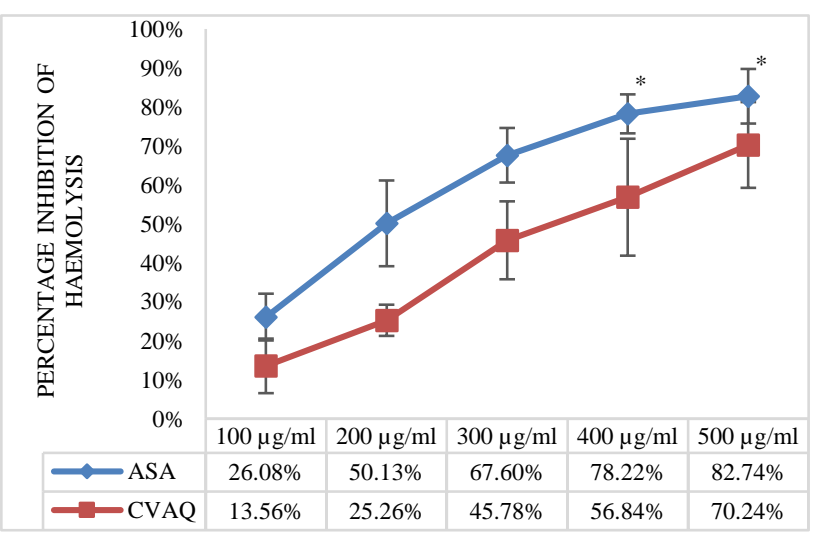

Figure 3: Percentage inhibition of haemolysis in heat induced haemolysis test.

Figure represented the percentage inhibition of haemolysis induced by heat. CVAQ = Aqueous extract of C. verrucosa . ASA = Acetyl salicylic acid. Data represented as mean+SEM and analyzed by one-way ANOVA followed by Dunnett $t$ test where $*$ denoted $\mathrm{p}<0.05$ as statistically significant. All groups $(n=3)$ were compared to control.

\section{Heat induced protein denaturation}

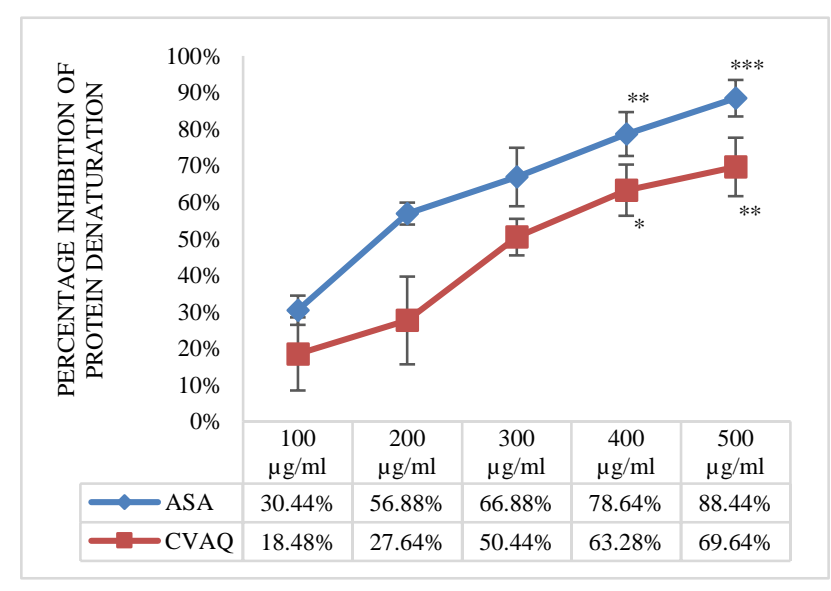

Figure 4: Percentage inhibition of protein denaturation in heat induced protein denaturation test.

Figure represented the percentage inhibition of protein denaturation induced by heat. CVAQ $=$ Aqueous extract of $C$. verrucosa. ASA = Acetyl salicylic acid. Data represented as mean+SEM and analyzed by one-way ANOVA followed by Dunnett $\mathrm{t}$ test where $*, * *$ and $* * *$ denoted $\mathrm{p}<0.05, \mathrm{p}<0.01$ and $\mathrm{p}<0.001$ respectively and as statistically significant. All groups $(n=3)$ were compared to control.

Like hemolysis test, ASA showed a gradual increase in inhibiting the percentage of protein denaturation which was statistically significant at $400(78 \%)$ and $500(88 \%)$ $\mu \mathrm{g} / \mathrm{ml}$ concentrations (Figure 4 ). In comparison, CVAQ at the same concentrations exhibited moderate suppression as $63 \%$ and $69 \%$ respectively.

\section{DISCUSSION}

Inflammation belongs to release of mediators and activation of receptors at the target site. Thus, antiinflammatory activity is obtained through a competitive binding of the antagonists to these receptors. In this study two in vivo methods were adopted having different inflammatory pathways and mediator's involvement so as to test the sample in broader spectrum. ${ }^{6}$ Carrageenan and xyline, two inflammatory substances which are still under investigation for their mechanism of triggering inflammation, were applied to living models. Standard anti-inflammatory agents were put in the frontline to understand the participation of mediators in each examination. Previous studies suggested carrageenan's potential to trigger a two-phase biological response initially by activating histamine, serotonin, kinin like mediators within first two hours and finally by releasing excessive prostaglandins, oxygen-derived free radicals and cyclooxygenase; where polymorphonuclear (PMN) leucocyte infiltration and a significant increase in the level of neutrophils were reported through observation of a large numbers of inflammatory cells in the paw tissues. $^{12,13}$ Unlike carrageenan, xyline is known to be partially associated with substance $\mathrm{P}$, a neuromodulator which is extensively distributed throughout the central and peripheral nervous system. Xyline facilitates the release of substance $\mathrm{P}$ causing neurogenic inflammation through vasodilatation and plasma extravasations. ${ }^{14}$ This event is caused by an innate immunity response produced by activated T-cells which results in migration of PMN leucocytes and augmentation of swelling and heaviness of the ear of mice. ${ }^{15}$

In both tests, indomethacin, a common non-steroidal antiinflammatory (NSAID) agent found to have strong involvement in suppressing the mediators whereas the greater efficacy shown by prednisolone was largely due to its steroidal properties. ${ }^{16-18}$ In comparison, the aqueous extract of $C$. verrucosa elucidated its potential for mediator suppression as similar to that of indomethacin, however the particular mediator involvement and the specific mechanism could not be predicted at this point of study without knowing the responsible components of the sample.

To support the claims, two in vitro study were performed to evaluate the protective ability of the sample towards protein denaturation and hemolysis. ${ }^{19} \mathrm{~A}$ chronic inflammatory response has been reported to occur due to 
protein denaturation, a biochemical reaction that could result in attenuation of tissue function. Pro-inflammatory markers are released by the lysis of lysosomal membranes during chronic inflammation which activates neutrophils, proteases and histamines at local site of tissue damage causing type III hypersensitivity reactions as well as the diseases like serum sickness. ${ }^{20,21}$ As conventional NSAID, acetyl salicylic acid (aspirin) not only blocked COX enzyme and synthesis of endogenous PGE2 but also found to suppress the process of protein denaturation. ${ }^{22}$ However, the leaf extract mimicked the NSAID to a moderate extent showing similar pattern in results. The other experiment suggested heat induced hemolysis is a result of erythrocyte membrane destabilization which promotes the production of free radicals, such as lipid peroxides and superoxides. ${ }^{23}$ As the leaves have been reported to contain flavonoids, tannins and other phenolic content which act as effective scavengers of free radicals, the biological membrane stabilization properties shown by its extract can be attributed to these chemicals which prevented stress-induced destruction of the plasma membrane. ${ }^{24}$

\section{CONCLUSION}

The findings of the study demonstrated that the aqueous leaf extract of $C$. verrucosa possess potential antiinflammatory activity. However, the study was yet to indicate the biological compounds, specific mediators' involvement and mechanism of suppression relating to this anti-inflammatory effect. Further investigation was recommended on phytochemical screening and in vitro analysis to establish the scientific basis of its activity.

\section{ACKNOWLEDGEMENTS}

The present study was supported and carried out in the Pharmacology lab of Institute for Pharmaceutical Skill Development and Research, Bangladesh. Authors are grateful to the institute for providing such opportunity to contribute to the health science.

\section{Funding: No funding sources}

Conflict of interest: None declared

Ethical approval: The study was approved by the Institutional Ethics Committee

\section{REFERENCES}

1. Kumar VS, Navaratnam V. Neem (Azadirachta indica): prehistory to contemporary medicinal uses to humankind. Asian Pac J Trop Biomed. 2013;3(7):505-14.

2. Nawrin K, Billah MM, Jabed MSU, Roy A, Ahmad AKMR, Islam MN. Antipyretic, Antidiabetic, Thrombolytic and CNS Depressant Potential of Ethanol Extract of Crotalaria verrucosa L. Leaves. Am J Biomed Sci. 2015;198-204.

3. RameshKannan N, John AA, Natarajan E. Inhibition of Ehrlich Ascites Carcinoma by Crotalaria verrucosa L. Leaf in Swiss Albino Mice. Res Rev J Ayurv Sci Yoga Naturoap. 2018;5(2):5-10.

4. Ahmed ZS, Nowrin T, Hossain MH, Nasrin T, Akter r. Metabolite Profiling of Crotalaria verrucosa Leaf Extract and Evaluation of its Antioxidant and Cytotoxic Potency. Res J Phytochem. 2018;12:60-70.

5. Sumi FA, Ansari P, Azam S, Nazneen S, Uddin N, Baidya T. In-vitro Investigation of Anti-Coagulation Property of Four Bangladeshi Plants of Crotalaria Species and Analysis of their Qualitative Bioactive Compounds. 2015;7(4):5.

6. Nawrin K, Billah MM, Jabed MSU, Khalil MI, Uddin MM, Islam MN. Suppression of Inflammatory Mediators by the Ethanol Extract of Crotalaria verrucosa L. leaf - in vivo and in vitro Analysis. Europ J Medic Plant. 2016;1-7.

7. Tang XC, Lin ZG, Cai W, Chen N, Shen L. Antiinflammatory effect of 3-acetylaconitine. Acta Pharm Sinica. 1984;5;85-9.

8. Winter CA, Risley EA, Nuss GW. Carrageenininduced edema in hind paw of the rat as an assay for antiiflammatory drugs. Proc Soc Exp Biol Med. 1962;111:544-7.

9. Adeyemi OO, Okpo SO, Ogunti OO. Analgesic and anti-inflammatory effects of the aqueous extract of leaves of Persea americana mill (lauraceae). Fitoterapia. 2002;73(5):375-80.

10. Anosike CA, Obidoa O, Ezeanyika LU. Membrane stabilization as a mechanism of the anti-inflammatory activity of methanol extract of garden egg (Solanum aethiopicum). Daru. 2012;20(1):76.

11. Carter SJ. Blood and related products. Part 3, Chapter 34, 6th ed. Pitman, London: Cooper and Gunn's Tutorial Pharmacy; 2000.

12. Ashok P, Koti BC, Thippeswamy AHM, Tikare VP, Dabadi P, Viswanathaswamy AHM. Evaluation of Antiinflammatory Activity of Centratherum anthelminticum (L) Kuntze Seed. Ind J Pharm Sci. 2010;72(6):697-703.

13. Zhang J, Wang H, Wang T, Chong Y, Yu P, Lu C, et al. Anti-inflammatory activity of Yanshu spraying agent in animal models. Experiment Therap Medic. 2013;5(1):73-6.

14. Agbaje EO, Fageyinbo MS. Evaluating AntiInflammatory activity of aqueous root extract of Strophanthus hispidus DC. (Apocynaceae). Int J Appl Res Nat Prod. 2012;4(4):7-14.

15. Sadeghi H, Zarezade V, Sadeghi H, Toori MA, Barmak MJ, Azizi A, et al. Anti-inflammatory activity of Stachys pilifera Benth. Iran Red Cresc Medic J. 2014;16(9).

16. Amann R, Schuligoi R. Inhibition of carrageenaninduced edema by indomethacin or sodium salicylate does not prevent the increase of nerve growth factor in the rat hind paw. Neurosci Lett. 2000;278(3):173-6.

17. Gamache DA, Ellis EF. Effect of dexamethasone, indomethacin, ibuprofen, and probenecid on carrageenan-induced brain inflammation. J Neurosurg. 1986;65(5):686-92. 
18. Okoye FBC, Osadebe PO, Proksch P, Edrada-Ebel RA, Nworu CS, Esimone CO. Anti-inflammatory and membrane-stabilizing stigmastane steroids from Alchornea floribunda leaves. Planta Med. 2010;76(2):172-7.

19. Smith J, Das B, Choudhury MD, Dey A, Talukdar AD, Nongalleima $\mathrm{K}$, et al. Antioxidant and antiInflammatory activity of aqueous and methanolic extracts of rhizome part of Drynaria quercifolia (1.) J Smith Int J Pharm Pharm Sci. 2014;6(6):43-9.

20. Anyasor GN, Okanlawon AA, Ogunbiyi B. Evaluation of anti-inflammatory activity of Justicia secunda Vahl leaf extract using in vitro and in vivo inflammation models. Clin Phytosci. 2019;5(1):49.

21. Ahmad F, Khan RA, Rasheed S. Study of Analgesic and AntiInflammatory Activity from Plant Extracts of Lactuca Scariola and Artemisia absinthium. Med J Islamic World Acad Sci. 1992;5(2):111-4.

22. Insel PA. Analgesic-antipyretics and antiinflammatory agents: Drugs employed in the treatment of rheumatoid arthritis and gout. In goodman and Gilman's the pharmacological basis of therapeutics. Edited by Gilman AG, Rall T, Nies A, Taylor P. Pergamon, NY. 1990:638-81.

23. Ranasinghe P, Ranasinghe P, Abeysekera WPKM, Premakumara GAS, Perera YS, Gurugama P, et al. In vitro erythrocyte membrane stabilization properties of Carica papaya L. leaf extracts. Pharmacogn Res. 2012;4(4):196-202.

24. Richards DM, Dean RT, Jessup W. Membrane proteins are critical targets in free radical mediated cytolysis. Biochim Biophys Acta. 1988;946(2):281-8.

Cite this article as: Billah MM, Huzaifa A, Khan MAK, Vabna NJ, Nawrin K, Rayhan MA.

Suppression of inflammatory mediators by aqueous leaf extract of Crotalaria verrucosa: in vivo and in vitro analysis. Int J Basic Clin Pharmacol 2020;9:1897-902. 